\title{
Acquired dyslexia in Mongolian
}

\author{
Brendan Stuart Weekes ${ }^{\text {a,* }}$, Kathrin Klingebiel ${ }^{\text {a }}$, I. Fan Su ${ }^{\text {a }}$, Qingfang Zhang ${ }^{\text {a }}$, \\ Xihong Zhang ${ }^{\mathrm{b}}$, Wengang Yin ${ }^{\mathrm{c}}$ \\ a Laboratory of Experimental Psychology, University of Sussex, Brighton BN2 9QN, UK \\ ${ }^{\mathrm{b}}$ Department of Neurology, Tongliao People's Hospital, China \\ ${ }^{\mathrm{c}}$ Chinese Academy of Science, China
}

Studies of bilingual aphasia suggest that brain damage produces dissociations in language processing i.e. one language more impaired than the other (Paradis, 1977). Some studies of patients with biscriptal aphasia suggest that differences in script have an impact on oral reading of patients with bilingual aphasia. Beland and Mimouni (2001) reported better reading of nonwords in French (L2) than Arabic (L1) and Eng and Obler (2002) reported more semantic reading errors in Chinese (L1) than English (L2). Caramelli, Parente, Hosogi, Bois, and Lecours (1994) reported more reading and writing errors in Japanese than Portuguese in a Brazilian "Nesei" patient even though the patient had acquired both languages at an early age and he was a scribe in Japanese premorbidly. Although these patients are biscriptal rather than bilingual, the data suggest that different scripts have separate functional anatomy compatible with the view that L1 and L2 are processed in different parts of the brain (Albert \& Obler, 1978; Benson, 1985; Cremaschi \& Dujovny, 1996). Almost all studies of biscriptal reading test in languages that share an alphabetic script. For example, Masterson, Coltheart, and Meara (1985) reported a Spanish-English speaker who produced more reading errors in English (L2) than Spanish (L1). Raman and Weekes, (2005) reported a similar pattern in a TurkishEnglish speaker. Although some studies have asked whether representations of written words are activate in both languages during bisciptal oral reading by making cross-script comparisons e.g., Hebrew-English (Gollan, Forster, \& Frost, 1997) or by testing languages with two different scripts e.g. Serbo-Croatian (Havelka \& Rastle, 2005), it remains an open question whether differences in script across the two languages of a biscriptal reader have any impact on language processing and specifically on oral reading in impaired (aphasic) speakers. The question we asked is whether script has an impact on written language processing in bilingual patients who speak two East-Asian languages with different orthography: Chinese and Mongolian.

\section{Case reports}

Two bilingual Mongolian-Chinese stroke patients (SL and LH) were recruited from Tongliao People's Hospital in Inner-Mongolia Autono-

\footnotetext{
Corresponding author. Fax: +4401227 827030.

E-mail address: B.S.Weekes@sussex.ac.uk (B.S. Weekes).
}

mous District. Patients were given four tasks: oral reading, lexical decision, written word-picture matching and spoken word-picture matching. Each task was presented on two occasions separated by at least a week and items were presented in either Mongolian (L1) or Chinese (L2) with order counterbalanced to minimise effects of expectation of a bilingual environment (Grosjean, 1998). Each task contained the same lexical items $(n=14)$ reported in the Appendix (star, cat, eye, ship, table, ox, square, grandmother, skirt, egg, elephant, bowl, fish, woman). Words were concrete nouns that are early acquired, high imageability and high frequency. Stimuli were thus familiar to all patients in both languages premorbidly. Results are summarised in Table 1. For patient SL, type of script had an effect on written word comprehension $X^{2}(1)=6.0, p<.05$, spoken word comprehension $X^{2}(1)=6.0, p<.05$ and reading $X^{2}(1)=5.0$, $p<.05$. However, lexical decision was preserved in both languages. SL produced semantic errors in Mongolian and Chinese and "translation errors" i.e. reading aloud a Chinese word with a Mongolian syllable. For patient LH there was an effect of script on reading $X^{2}(1)=4.0$, $p<.05$. LH produced semantic errors in Mongolian e.g. table read as stool but not in Chinese. We performed further testing with SL and LH on all tasks one month after first testing. Performance at second testing (Time 2) is summarised in Table 1. For SL, effects of script on lexical processing were no longer significant at Time 2. For LH, the effect of script at Time 2 was significant for oral reading only $X^{2}(1)=7.0, p<.05$. Thus, the effects of script on lexical processing observed at initial testing had a sustained impact on oral reading for patient LH only.

\section{Discussion}

Some cognitive models of bilingual language processing assume that knowledge about word meaning (semantic representations) is shared across languages whereas the representations for word forms are stored in separate lexica (e.g. Potter, So, Von Eckardt, \& Feldman, 1984; Smith, 1997). The Revised Hierarchical (RH) model (Kroll \& Stewart, 1994) assumes that access to word meanings from the most familiar word forms (typically L1) is more efficient than access from less familiar forms. The RH model can explain selective effects of brain damage in bilingual aphasia because the store of word forms in one language can be damaged without damage to the other. Although the assumption of common conceptual representations in L1 and L2 is not controversial (see Francis, 1999), other models do not assume independent lexica. For example, the Bilingual 
Table 1

Results of experimental investigations for patients SL and LH (\% correct)

\begin{tabular}{lrrrr}
\hline & SL time 1 & SL time 2 & LH time1 & LH time 2 \\
\hline Mongolian & & & & \\
Reading & 57 & 92 & 28 & 92 \\
Lexical decision & 100 & 100 & 50 & 100 \\
Written-picture & 92 & 100 & 78 & 100 \\
Spoken-picture & 100 & 100 & 78 & 100 \\
Chinese & & & & \\
Reading & 14 & 85 & 0 & 42 \\
Lexical decision & 100 & 100 & 71 & 78 \\
Written-picture & 50 & 100 & 78 & 71 \\
Spoken-picture & 57 & 100 & 78 & 78 \\
\hline
\end{tabular}

Interactive Activation (BIA) model (Dijkstra \& van Heuven, 1998) that assumes orthographic representations of word forms in each language are stored at the same level of processing. This model can account for selective effects of language on performance by assuming that nodes representing words in the dominant language have a higher average resting level than less dominant language nodes. Note dominant refers to the more familiar language, which may or may not be the first acquired. The BIA model assumes that lexical processing of written word forms in L1 and L2 address the same lexical representation. Therefore, the BIA model would expect impaired processing of written word forms in one script to be accompanied by impaired written word processing in the other script and has difficulty explaining an effect of script on oral reading when items are controlled for familiarity. The data suggest that reduced activation following brain damage may have a selective impact on written word processing in bilingual aphasia even if word forms are familiar, imageable and early acquired. One question for future research is whether lesioning computational models would simulate these effects.

\section{Acknowledgments}

This work was supported by research grants from the Royal Society and the Research Grants Council of the Hong Kong Government (HKU7275/03H).

\section{References}

Albert, M. L., \& Obler, L. K. (1978). The bilingual brain: Neuropsychological and neurolinguistic aspects of bilingualism. New York: Academic Press.
Beland, R., \& Mimouni, Z. (2001). Deep dyslexia in the two languages of an Arabic/French bilingual patient. Cognition, 82, 77-126.

Benson, D. F. (1985). Aphasia. In K. Heilman \& E. Valenstein (Eds.). Clinical neuropsychology (Vol. 2). New York: Oxford Univ. Press.

Caramelli, P., Parente, M. A. M. P., Hosogi, M. L., Bois, M., \& Lecours, A. R. (1994). Unexpected reading dissociation in a Brazilian Nisei with crossed aphasia. Behavioural Neurology, 7, 156-164.

Cremaschi, F., \& Dujovny, E. (1996). Japanese language and brain localization. Neurological Research, 18(3), 212-216.

Dijkstra, A., \& van Heuven, W. J. B. (1998). The BIA model and bilingual word recognition. In J. Grainger \& A. Jacobs (Eds.), Localist connectionist approaches to human cognition (pp. 189-225). Mahwah: Lawrence Erlbaum Associates.

Eng, N., \& Obler, L. K. (2002). Acquired dyslexia in a biscript reader following traumatic brain injury: A second case. Topics in Language Disorders, 22(5), 5-19.

Francis, W. S. (1999). Cognitive integration of language and memory in bilinguals: Semantic representation. Psychological Bulletin, 125 , 193-222.

Gollan, T. H., Forster, K. I., \& Frost, R. (1997). Translation priming with different scripts: Masked priming with cognates and noncognates in Hebrew-English bilinguals. Journal of Experimental Psychology: Learning, Memory, and Cognition, 23, 1122-1139.

Grosjean, F. (1998). Studying bilinguals: Methodological and conceptual issues. Bilingualism: Language and Cognition, 1, 131-149.

Havelka, J., \& Rastle, K. (2005). The assembly of phonology from print is serial and subject to strategic control: Evidence from Serbian. Journal of Experimental Psychology: Learning, Memory, \& Cognition, 31, $148-158$

Kroll, J. F., \& Stewart, E. (1994). Category interference in translation and picture naming: Evidence for asymmetric connections between bilingual memory representations. Journal of Memory and Language, 33, $149-174$.

Masterson, J., Coltheart, M., \& Meara, P. (1985). Surface dyslexia in a language without irregularly spelled words. In K. Patterson, J. C. Marshall, \& M. Coltheart (Eds.), Surface dyslexia: Neuropsychological and cognitive studies of phonological reading (pp. 215-223). London: LEA.

Paradis, M. (1977). Bilingualism and aphasia. In H. Whitaker \& H. A. Whitaker (Eds.). Studies in neurolinguistics (Vol. 3, pp. 65-121). New York: Academic Press.

Potter, M. C, So, K. F., Von Eckardt, B., \& Feldman, L. (1984). Lexical and conceptual representation in beginningand proficient bilinguals. Journal of Verbal Learning and Verbal Behavior, 23, 23-38.

Smith, M. C. (1997). How do bilinguals access lexical information? In A. M. De Groot \& J. F. Kroll (Eds.), Tutorials in bilingualism: Psycholinguistic perspectives (pp. 145-168). Hillsdale, NJ: Erlbaum. 